
A $\mathbf{R}_{\text {Eview }}$
FOOD SCIENCE
RESEARCH JOURNAL
- Visit us : www.researchjournal.co.in Volume 9 | Issue 2 | October, 2018 | 441-447
DOI : $10.15740 / \mathrm{HAS} / \mathrm{FSRJ} / 9.2 / 441-447$

\title{
Nanotechnology in food preservation
}

\author{
Priyanka Singh
}

\begin{abstract}
Nanotechnology deals with the atoms, molecules, or the macromolecules with the size of approximately 1-100 nm to create and use materials that have novel properties. The created nanomaterials possess one or more external dimensions, or an internal structure, on the scale from 1 to $100 \mathrm{~nm}$ that allowed the observation and manipulation of matter at the nanoscale. In functional foods where bioactive component often gets degraded and eventually led to inactivation due to the hostile environment, nanoencapsulation of these bioactive components extends the shelf-life of food products by slowing down the degradation processes or prevents degradation until the product is delivered at the target site. Microbial contamination has been leading to pathogenic infections and poor nutrition associated with foods. Novel nanoantimicrobials have shown promising effects on safeguarding food deterioration.Nano-based "smart" and "active" food packagings confer several advantages over conventional packaging methods from providing better packaging material with improved mechanical strength, barrier properties, antimicrobial films to nanosensing for pathogen detection and alerting consumers to the safety status of food.In this review, we mainly focus on the technology of nanoencapsulation in food preservation, and also discussed some negative facts associated with this technology.
\end{abstract}

Key Words : Nanotechnology, Nanoantimicrobials, Nanosensing, Nanoencapsulation

How to cite this article : Singh, Priyanka (2018). Nanotechnology in food preservation. Food Sci. Res. J., 9(2): 441-447, DOI : 10.15740/HAS/FSRJ/9.2/441-447.Copyright@ 2018: Hind Agri-Horticultural Society. 